\title{
Dapoxetine, a novel selective serotonin transport inhibitor for the treatment of premature ejaculation
}

\author{
Muammer Kendirci ${ }^{1}$ \\ Emad Salem ${ }^{2}$ \\ Wayne JG Hellstrom ${ }^{2}$ \\ 'Department of Urology, Sisli Etfal \\ Training and Research Hospital, \\ Istanbul, Turkey; ${ }^{2}$ Department of \\ Urology, Tulane University Health \\ Sciences Center, New Orleans, LA, \\ USA
}

\begin{abstract}
Premature ejaculation (PE) is the most common male sexual disorder, estimated to affect up to $30 \%$ of men. Over the past one or two decades, clinical investigators have participated in an increasing number of studies that are helping in our understanding of PE, which will undoubtedly facilitate future treatments. Apart from a number of behavioral approaches, the treatment of PE consists of primarily off-label use of oral selective serotonin reuptake inhibitors (SSRIs) via either on-demand or daily delivery. However, various undesirable side-effects of these medications have led researchers to search for and develop new therapeutic approaches for PE. Dapoxetine is a short-acting SSRI developed specifically for the treatment of PE. Early trials with dapoxetine have documented successful outcomes without serious short- or longterm side-effects. This review addresses the definition, classification, diagnosis, physiology, and neurobiopathology of PE, and evaluates therapeutic strategies with novel treatments for PE.

Keywords: dapoxetine, premature ejaculation, selective serotonin reuptake inhibitor, sildenafil, topical cream, paroxetine, fluoxetine, sertraline
\end{abstract}

\section{Introduction}

Premature ejaculation (PE) is the most common male sexual disorder, and is estimated to affect up to $30 \%$ of men worldwide (Goldstein 2003). PE, unlike erectile dysfunction (ED), affects men of all ages equally, from 18-year-olds to the elderly. However, both $P E$ and ED coexist, and often PE can masquerade or be misdiagnosed as ED in many men. This is, in part, due to the lack of knowledge about PE, the absence of performing a careful history, and the non-existence of diagnostic tools for PE (Montague et al 2004). Despite its high prevalence and recognized adverse effects on men's quality of life, only recently has attention been focused on investigating the causes of PE and developing new therapeutic strategies.

Over the past 20-30 years, clinical investigators have participated in a growing number of controlled studies that are developing our basic understanding about PE in ways that will facilitate its future treatment (Waldinger 2002). The emergence of well-conducted clinical trials has created a greater understanding of the prevalence of PE, its etiology and pathophysiology, and, additionally, its impact on patient and partner quality of life. However, there are currently no regulatory or FDA-approved pharmacological therapies for treating PE.

This communication will focus on the prevalence, etiology, pathophysiology, and the current treatment options for PE. More specifically, a novel selective serotonin reuptake inhibitor (SSRI), dapoxetine, will be evaluated for its pharmacokinetics, efficacy, and safety record in light of available preclinical and clinical data.

\section{Definition}

Though PE is a non-life-threatening condition, like ED, it has a serious impact on patient and partner quality of life. The lack of agreement on a single precise definition of PE 
has hampered scientific research on the causes and management of PE (McMahon et al 2004). Various definitions of PE have been used by different researchers, and include partner satisfaction, male voluntary control, duration of ejaculatory latency, and number of intravaginal thrusts (Jannini et al 2002). A universally accepted definition of $P E$ has yet to be established. Masters and Johnson proposed one of the earliest definitions of $\mathrm{PE}$, as the inability to delay ejaculation long enough for the woman to achieve orgasm $50 \%$ of the time, assuming the PE was the sole cause of the female anorgasmia (Masters and Johnson 1970). Kaplan first suggested that PE was primarily a problem of voluntary control over timing of ejaculation, a concept on which most of the current definitions are based (Kaplan et al 1974). The Diagnostic and Statistical Manual of Mental Disorders, 4th ed (DSM-IV-TR), defines PE similarly but has an added emphasis on the emotional and interpersonal impact of early ejaculation The American Urological Association Guideline on Premature Ejaculation defines PE as “... ejaculation that occurs sooner than desired, either before or shortly after penetration, causing distress to either one or both partners" (Montague et al 2004).

In 1994, Waldinger et al (1994) introduced and defined intravaginal ejaculatory latency time (IELT) as an objective measure for ejaculation time. The IELT is defined as the time from vaginal intromission to intravaginal ejaculation. A distinct advantage of using the IELT is its clear starting and end points, which are important for comparative research purposes. An ejaculation that occurs before intromission has an IELT rating of 0 . The range of IELT used to identify PE varies in most studies from 1 to 7 minutes, even though no well-controlled studies have been undertaken regarding "normal" ejaculatory latency times in men across the typical life span (Symonds et al 2003). Recently, a large US-European cohort study was conducted to analyze the distribution of IELT in men from different countries (Waldinger et al 2005a). This study demonstrated that the shape of the IELT distribution is positively skewed, with a median IELT of 5.4 minutes (range 0.55-44.1 minutes). By applying the 0.5 and 2.5 percentiles as accepted standards of disease definition in a skewed distribution, it appeared that the 0.5 percentile equated to an IELT of 0.9 minutes and the 2.5 percentile to an IELT of 1.4 minutes. Based on these calculations, Waldinger et al (2005c) proposed a definition of lifelong $\mathrm{PE}$ as a neurobiological dysfunction with an unacceptable increase in the risk of developing sexual and psychological problems at any time during life. Moreover, it was proposed that all men with an IELT of less than 1 minute (belonging to the 0.5 percentile) have "definite" $P E$, while men with IELTs between 1 and 1.5 minutes (between 0.5 and 2.5 percentiles) have "probable" PE. In addition, the severity of PE (nonsymptomatic, mild, moderate, and severe) was proposed to be defined in terms of associated psychological problems. The advantage of this definition is the inclusion of both a quantitative biological measure, ie, the IELT, as well as the inclusion of qualitative psychological measures, ie, amount of distress and other psychological parameters, which determine the severity of PE. Most current clinical studies of PE use IELT as their primary quantitative or objective end-point to measure therapeutic efficacy (Rowland et al 2004). However, subjective patient reported outcome (PRO) measures, such as distress, dissatisfaction with sexual intercourse, relationship difficulties, and perception of ejaculatory control, are also vitally important in assessing the condition, and are recognized as other indicators for therapeutic efficacy and ejaculatory function (Rowland et al 2004).

\section{Classification of PE}

PE has been classified as either primary (lifelong) that begins when a male first becomes sexually active or secondary (acquired), meaning that a male previously had an acceptable level of ejaculatory control and developed the condition later in life (Williams 1984; Godpodinoff 1989). Primary PE is hypothesized to have a strong biological component with a variable psychological contribution. Although psychological or situational stressors may contribute to secondary PE, certain medical conditions and medications may also be associated. Another classification invokes the terms "global" or "universal" (eg, occurs regardless of situation or partner) or "situational" (eg, limited to certain situations or partner) (McMahon et al 2004). Lifelong (primary) or global PE suggests an organic basis that would be optimally treated by pharmacotherapy (McMahon et al 2004). Even though combined categories of ejaculatory disorders have a reported prevalence at some time in a man's life of up to $75 \%$, their causes are complex, comprising psychological, physiological, and interpersonal components (Shenassa and Hellstrom 2001). Upon reviewing PE data, lifelong PE is described as a triad of symptoms: ejaculation after few penile thrusts, a short IELT (less than 2 minutes), and occurrence of early ejaculation during (nearly) every coitus (Waldinger and Schweitzer 2005).

\section{Epidemiology}

Studies indicate that PE is the most common male sexual disorder (Laumann et al 1999; Rowland et al 2004). According to recent studies, $20 \%-30 \%$ of the male population is 
affected by $\mathrm{PE}$ at any one time, and some researchers believe that up to 3 out of 4 men experience PE sometime during their lives, although the majority never raise the subject with their physician (McMahon 1998). Laumann et al (1999) analyzed NHSLS data that included 1410 men and 1749 women aged 18-59 years, and reported the prevalence of PE as approximately $30 \%$. The Global Study of Sexual Attitudes and Behaviors investigated 13,618 men in 19 countries aged 40-80 years regarding aspects of sex and relationships (Laumann et al 2005). This survey reported that PE occurs in nearly $30 \%$ of men worldwide. A web-based study by Rowland et al (2004) that included 2648 male participants reported a prevalence of "possible PE" as $16.2 \%$ and "probable PE" as $16.3 \%$. In reviewing the relationship between the prevalence of PE and ethnicity, significant PE was reported by $29 \%$ of Hispanics, $21 \%$ of non-Hispanic blacks, and $16 \%$ of non-Hispanic whites (Carson et al 2003). In their analysis of NHSLS data, Laumann et al (1999) noted that PE was more prevalent amongst black men (34\%) and white men (29\%) than among Hispanic men (27\%).

Rosen et al (2004) conducted a multinational Internet survey among men in Italy, Germany, and the United States. Of 8860 men aged 25-70 years who completed questions 1 through 54 of the survey on general health and sexual attitudes, $26 \%$ overall were classified as having PE. Moreover, PE was often associated with ED. Another large survey that included 12,134 men from a number of countries documented that $7.2 \%$ of men met criteria for both PE and ED (Shabsigh and Perelman 2005). Overall, 31\% of men with PE had ED, whereas $44 \%$ of men with ED also reported PE.

\section{Physiology of ejaculation}

There are three basic mechanisms involved in normal antegrade ejaculation: emission, expulsion, and orgasm, and each of these components possesses separate neural pathways. Ejaculatory dysfunction can result from disruption of any point in this cascade of events. Several recent studies have clarified some aspects of the physiology of ejaculation. Emission, which begins with closure of the bladder neck to prevent retrograde flow of seminal fluid and sperm into the bladder, refers to the deposition of seminal fluid and sperm from the distal epididymis, vas deferens, seminal vesicles, and prostate into the posterior urethra (Witt and Grantmyre 1993).

Expulsion refers to the forcible antegrade propulsion of semen through the urethral meatus, which is caused by contractions of the periurethral and pelvic floor muscles and concurrent relaxation of the external urethral sphincter and urogenital diaphragm. The sympathetic nervous system controls both emission and bladder neck closure, and acts through alpha adrenergic receptors. The neural signals that lead to ejaculation originate from afferent-sensory stimuli in the glans penis and genitalia. These stimuli are transmitted by means of the pudendal nerve to higher centers in the brain (Witt and Grantmyre 1993).

Orgasm is a totally separate event, a sensory experience with considerable subjective variation; it can occur independently of ejaculation and even erection. After ejaculation, detumescence occurs, followed by a refractory period that lengthens with age and with repeated ejaculations. Researchers have demonstrated that the ejaculatory mechanism consists of two distinct reflexes, the glans-vasal and the urethromuscular, which are responsible for the emission and expulsion phases of ejaculation, respectively (Shafik 1998). This is consistent with the report by Yang and Bradley (1999) of an electrically distinct pathway localized to the dorsal nerve of the penis and running from the anterior urethra to the bulbocavernous muscle; this is distinct from the penile shaft afferent fibers. The cortical representation of the dorsal nerve of the penis now appears both larger and in a different location than was previously conceived (Bradley et al 1998).

In a canine electro-ejaculation study, Shafik et al (1997) proposed that the observed increase in activity of the puborectalis, levator ani, and external anal and external urethral sphincter muscles would express the prostatic secretions into the posterior urethra, elevate the prostate, and partially straighten the prostato-membraneous urethral kink that occurs during erection and thereby prevent the leakage of feces, flatus, and urine during coitus. These investigators theorized that the rhythmic external urethral sphincter contractions that occur at the time of ejaculation act as a "suction ejection pump", sucking the genital fluid into the posterior urethra while being relaxed and expulsing it into the bulbous urethra upon contraction.

\section{Neurobiological implications of ejaculation}

Serotonin is a very important neurotransmitter in the control of the ejaculatory reflex, with secondary involvement of cholinergic, adrenergic, oxytocinergic, and GABAergic neurons. The strongest support for serotonin's influence on ejaculatory function derives from the observed clinical efficacy of central selective seratonin reuptake inhibitors (SSRIs) in PE (Kim and Seo 1998; Waldinger et al 1998b). Seratoninergic neurons originate in the raphe nuclei and adjacent reticular formation of the brainstem (Waldinger 2005). After its 
production in the cell body, serotonin passes through the serotonergic neuron to the presynaptic membrane, where it is released into the synapse and acts on the postsynaptic receptors. By the action of serotonin transporters (5-HTT) on the presynaptic membrane, serotonin is returned to the presynaptic neuron. The process of serotonin release and its action on postsynaptic receptors is referred to as serotonergic neurotransmission (Waldinger 2005).

The involvement of central serotonergic neurotransmission in ejaculation has been investigated in a number of animal studies. The drug stimuli of the SSRIs fluoxetine and paroxetine most closely resemble $5-\mathrm{HT}_{2 \mathrm{C}}$ receptor activation (Berendsen and Broekkamp 1994). The activation of both $5-\mathrm{HT}_{2 \mathrm{~A}}$ and 5- $\mathrm{HT}_{2 \mathrm{C}}$ receptors by 2,5-dimethoxy-4-iodophenyl-2-aminopropane increases ejaculatory latency (Foreman et al 1989), while the selective 5- $\mathrm{HT}_{2 \mathrm{~A}}$ receptor agonist 2,5dimethoxy-4-methylamphetamine does not exhibit this effect (Ahlenius et al 1981). On the other hand, selective activation of 5-HT $\mathrm{HA}_{1 \mathrm{~A}}$ receptors by 8-hydroxy-2-(di-n-ropylaminotetralin) shortens the ejaculatory latency time and reduces the number of intromissions preceding ejaculation in animals (Ahlenius et al 1981). SSRIs block the 5-HT transporters, both in the presynaptic membrane and the cell-body. As a consequence, serotonin levels increase outside the cell-body and in the synapses (Waldinger 2005). Due to increased serotonin levels by SSRIs, 5-HT ${ }_{1 \mathrm{~A}}$ autoreceptors at the surface of the cell-body and 5- $\mathrm{HT}_{1 \mathrm{~B}}$ autoreceptors in the presynaptic membrane become activated (Waldinger et al 1998a, 2005b). The initial activation of both somatodendritic 5- $\mathrm{HT}_{1 \mathrm{~A}}$ autoreceptors and the presynaptic 5-HT ${ }_{1 \mathrm{~B}}$ autoreceptors results in an inhibition of 5-HT release into the synaptic cleft. Consequently, after acute SSRI administration, serotonin concentrations in the synapse generally diminish, but may be active due to the blockage of the 5-HT transporters causing some slight stimulation of all postsynaptic 5-HT receptors (Waldinger et al 1998a, 2005b). However, after chronic SSRI administration, the 5- $\mathrm{HT}_{1 \mathrm{~A}}$ and 5- $\mathrm{HT}_{1 \mathrm{~B}}$ autoreceptors become desensitized, resulting in a diminished inhibitory action of these receptors to 5-HT release. Consequently, serotonin is again released into the synapse.

Male rat studies have demonstrated that the neurotransmitter serotonin and two 5-HT receptors are involved in the ejaculatory process (Ahlenius et al 1981; Foreman et al 1989). Activation of 5- $\mathrm{HT}_{2 \mathrm{C}}$ receptors delays ejaculation, whereas activation of 5- $\mathrm{HT}_{1 \mathrm{~A}}$ receptors accelerates ejaculatory latency (Ahlenius et al 1981). Based on these animal studies, Waldinger et al (1998a) hypothesized that lifelong PE is a neurobiological phenomenon related to decreased central serotonergic neurotransmission, caused by a disruption in the functional balance of 5-HT receptor subtypes: increased sensitivity of 5-HT ${ }_{1 \mathrm{~A}}$ receptors with decreased sensitivity of $5-\mathrm{HT}_{2 \mathrm{C}}$ receptors. Hence, they suggest that treatment for PE should aim at $5-\mathrm{HT}_{2 \mathrm{C}}$ receptor stimulation and/or $5-\mathrm{HT}_{1 \mathrm{~A}}$ receptor inhibition (Waldinger et al 2005b).

\section{Animal studies for the treatment of PE}

Development of new serotonergic drugs seems inevitable in light of the high incidence and the need for effective treatment of premature ejaculation. Thus, the development of an in vivo experimental model for objectively assessing the efficacy of these new drugs is mandatory. Hsieh et al (1998) previously established a rat model involving electrical stimulation of the lesser splanchnic nerve to induce changes in the intraluminal pressure of the seminal vesicle. These investigators evaluated the impact of various agents, such as prazosin, 5-hydroxy tryptamine, clomipramine, fluoxetine, imipramine, and indatraline, on seminal vesicle pressure induced by electrical stimulation. They documented concentration-dependent effects with prazosin and all serotonergic agents, but not with imipramine or indatraline. Fluoxetine was reported to have the highest efficacy. On the other hand, Kim et al (2000) studied the effects of serotonergic drugs including clomipramine, sertraline, paroxetine, and fluoxetine on the vasal pressure induced by electrical stimulation of the hypogastric nerve (Kim et al 2000). All these serotonergic drugs were documented to cause concentration-dependent inhibition of intraluminal pressure elevation in the vas deferens. These investigators reported clomipramine as having the strongest inhibitory effect followed by sertraline, paroxetine, and fluoxetine (Kim et al 2000).

Recently, Kim et al (2004) established an in vivo experimental model in which the intraluminal pressure responses of both the seminal vesicle and vas deferens could be measured simultaneously in a single animal. They stimulated the hypogastric nerve as it was more specific in action or distribution than the lesser splanchnic nerve in inducing contraction of the seminal tract by electrical stimulation. The basic hypothesis of this study was that drugs for the treatment of PE produce their effects by inhibiting intraluminal pressure elevations of the seminal tract. All serotonergic agents tested significantly inhibited the increase in seminal vesicle pressure induced by hypogastric nerve stimulation. All serotonergic drugs were documented to exhibit significant inhibitory effects on the contractile responses of the seminal vesicle, whereas minimal (ser- 
traline) to no effects (fluoxetine and paroxetine) were observed in the vasal pressure responses. As $50 \%-70 \%$ of the ejaculatory volume is produced by the seminal vesicle, this organ is a greater contributor than the vas deferens in ejaculatory volume (Coffey 1988). Thus, the reasoning is that an inhibitory effect on seminal vesicle pressure is more important than the effect on vasal pressure.

In the human, electrical stimulation of either the presacral nerve (superior hypogastric ganglion) or hypogastric nerve causes contraction of the bladder neck, seminal vesicles, vas deferens, and ejaculatory ducts (Kim et al 2004). The mild delaying effect in humans of fluvoxamine on ejaculation relative to paroxetine has been demonstrated in a placebocontrolled male rat study using a chronic administration treatment model (Waldinger et al 1998b, 2002). However, this difference in the effects between these two agents has not been observed in the acute treatment model (Mos et al 1999).

\section{Treatment}

\section{Psychological/behavioral therapy}

Behavioral therapy was first advocated by Semans in 1956 with the "squeeze technique" and later popularized in the 1970 s by Masters and Johnson. This technique involves withdrawal of the penis during intercourse prior to the mo- ment of ejaculatory inevitability, and the partner is asked to apply a sharp squeeze to the glans to abort ejaculation.

The stop-start technique has since been popularized by Kaplan in 1983. In this technique the man is asked to pause during sexual stimulation, just prior to impending ejaculation. This pause allows the patient to acclimatize to the sensation and to condition himself to increased ejaculatory control. This technique helps the patient to heighten his awareness of sexual sensations. Unfortunately, many others have found that any initial success achieved by behavioral therapy was not maintained at 3-year follow-up (Sharlip 2005). Non-pharmacological treatment options for PE are provided in Figure 1.

\section{Topical anesthetics}

A number of creams and gels are available that desensitize the penis and may in effect delay orgasm in men with PE. After a man applies one of these agents to his penis, he proceeds to sexual activity with or without use of a condom. If he removes the condom, he should wash the penis to remove any remaining compound, thus reducing or avoiding the chances of desensitizing or numbing his partner's genitalia.

The use of topical anesthetic ointments is probably the oldest treatment for delaying ejaculation, but only a few controlled studies gave been reported. In one study, the results

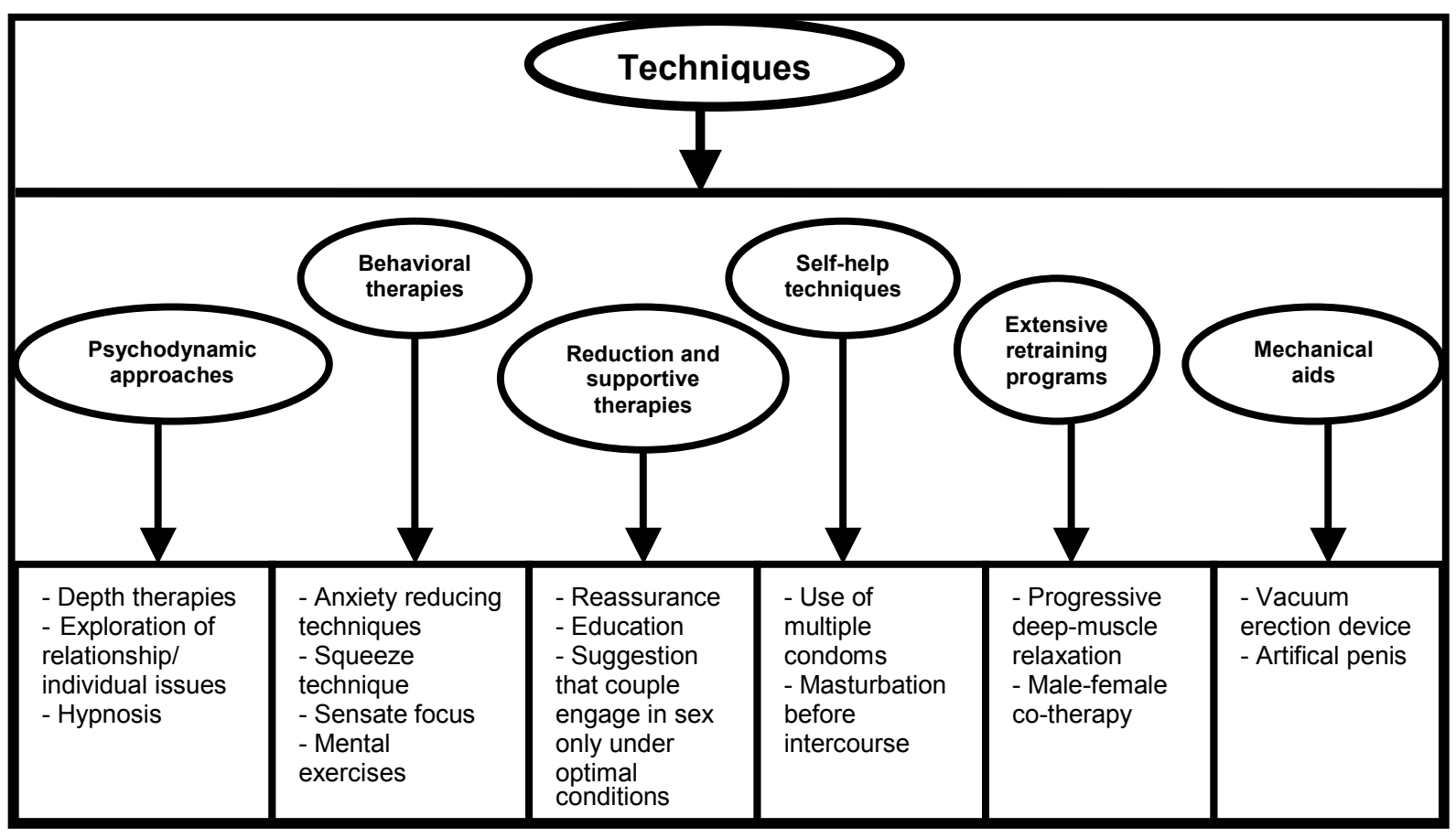

Figure I Non-pharmacological treatment options for PE. Adapted from Shenassa and Hellstrom (200I). 
of lidocaine-prilocaine cream 10 minutes before intercourse were described (Berkovitch et al 1995). Also, an aerosol formulation of lidocaine-prilocaine is effective in prolonging IELT and in improving sexual satisfaction in men with PE and their partners. The main drawback of topical anesthetics is their potential to cause a reduction in penile sensation and vaginal numbness in his partner.

In Korea, positive results were reported with SS-cream, a regionally manufactured agent consisting of the extracts of nine natural herbal products proposed to decrease penile hypersensitivity and or hyperexcitability (Xin et al 1997; Choi et al 2000). These investigators examined the efficacy of SScream in a double blind, randomized, placebo-controlled study in 106 men with lifelong PE. During the screening phase of the study, the men's mean IELT was $1.37 \pm 0.12$ minutes and both the men and their partners reported being dissatisfied with their sexual lives (Choi et al 2000). During the treatment phase, which consisted of 6 separate applications (one of which was a placebo), the men applied the cream to the glans penis 1 hour before intercourse. After treatment the men's mean IELT increased to $2.45 \pm 0.29$ minutes with placebo and to 10.92 \pm 0.29 minutes with use of SS-cream. Side-effects included local burning and mild pain, which was reported in $18.49 \%$ of the 530 active treatment applications, but these symptoms disappeared in less than 1 hour. No adverse effects on sexual function or systemic side-effects were noted.

\section{SSRIS}

SSRIs are widely used pharmacotherapeutic agents. The potential of antidepressants to treat PE was first introduced by Ahlenius et al (1981). This group showed that the tricyclic antidepressant clomipramine prolonged ejaculatory latency in rats by blocking central serotonin reuptake. However, as postsynaptic $5-\mathrm{HT}_{1 \mathrm{C}}$ receptors are minimally stimulated after a few hours of SSRI administration, it can be predicted that on-demand SSRI treatment will have only a slight ejaculation-delaying effect (Waldinger 2005). The absence of a significant ejaculation delay after acute SSRI administration has been demonstrated in animal sexual behavioral studies (Mos et al 1999).

Although, many studies have been published on the use SSRIs in the treatment of PE, Waldinger et al were the first to evaluate these studies methodologically in light of evidence-based criteria (Waldinger 2003; Waldinger et al 2004b). The results revealed that from 79 publications on drug treatment of PE, 35 studies involved serotonergic antidepressants. He clearly documented that in both singleblind and open-design studies, as well as studies using a questionnaire or subjective report on ejaculation time, there was a high variability, and that there was over-estimated responses in the degree of ejaculatory delay. Only 8 studies $(18.5 \%)$ fulfilled all criteria of evidence-based medicine, eg, double-blind studies prospectively using real-time stopwatch assessments at each intercourse both at baseline and during the drug trial (Waldinger 2003, 2005; Waldinger et al 2004b). For daily treatment, a rank order of efficacy of the SSRIs was established, with clomipramine being the best, followed by paroxetine, sertraline, and fluoxetine.

In a double-blind stopwatch study in men with lifelong PE associated with an IELT of less than 1 minute, Waldinger et al (2004a) found that on-demand treatment with $20 \mathrm{mg}$ paroxetine exerted only a 1.41 -fold increase in IELT at a drug coitus interval time (DCIT) of 5.30 hours (Waldinger et al 2004a). The calculated 1.41-fold increase means that on-demand treatment with $20 \mathrm{mg}$ paroxetine induced only a $40 \%$ ejaculation delay. The degree of ejaculation delay in this study was considered as clinically insignificant by the men and their female partners. On the other hand, ondemand treatment with $25 \mathrm{mg}$ clomipramine with a mean DCIT of 5.15 hours led to a 4.05-fold increase in the IELT, which was considered as clinically relevant by the couples, and confirmed earlier reports on the efficacy of on-demand clomipramine treatment (Segraves et al 1993; Haensel et al 1996; Waldinger et al 2004a).

Interestingly, other studies on paroxetine on-demand use for PE demonstrated stronger ejaculatory-delaying effect (McMahon and Touma 1999; Abdel-Hamid et al 2001). In the first study, Abdel-Hamid et al (2001) reported a 4-fold ejaculation delay with on-demand $20 \mathrm{mg}$ paroxetine, administered 3-4 hours prior to coitus. Similarly, McMahon and Touma (1999), using a single-blinded design, reported an 11-fold ejaculation delay without remarkable serotonergic side-effects, with $20 \mathrm{mg}$ paroxetine administered 3-4 hours before coitus. However, such a strong delay with on-demand treatment in the absence of serotonergic side-effects does not seem likely, as this implies better effects with on-demand treatment than previously reported daily treatment with $20 \mathrm{mg}$ paroxetine (Waldinger 2005). As an absence of ejaculation delay with acute SSRI administration has been demonstrated in a number of animal sexual behavioral studies and based on current knowledge with conventional SSRIs, it is unlikely that on-demand use of SSRIs will delay ejaculation within 1-2 hours of intake (Mos et al 1999; Waldinger 2005). Based on animal studies, Waldinger et al $(2005 \mathrm{~b})$ postulated that on-demand treatment of PE with conventional SSRIs will only be successful when an SSRI is combined with a 5-HT1A 
receptor antagonist, or another serotonergic intervention that acutely stimulates serotonergic release.

For these reasons, daily administration of the SSRIs seems the likely choice for the treatment of PE. After a few weeks, as the 5-HT $1 \mathrm{~A}$ and $5-\mathrm{HT}_{1 \mathrm{~B}}$ autoreceptors become desensitized, serotonin is increased in the synapse region (Waldinger 2005). With SSRI-induced blockage of the 5-HT transporters, serotonin cannot return to the presynaptic neuron, and as a consequence, serotonin levels in the synapse rise. It is the activity of the postsynaptic receptors that ultimately determines the clinical effects of daily administration of SSRIs (Waldinger 2005).

Studies on the use of various SSRIs are summarized in Table 1.

\section{Type 5 phosphodiesterase (PDE-5) inhibitors}

Recently several studies have suggested that sildenafil may be beneficial in the treatment of PE, either as a single agent or in combination with SSRIs. In the study by Abdel-Hamid et al (2001), 31 patients with lifelong PE underwent treatments with clomipramine, sertraline, and paroxetine, the squeeze technique, or sildenafil in a randomized crossover design. Sildenafil was administered as needed 3-5 hours before planned sexual intercourse. The authors reported that sildenafil was superior to all of the SSRIs and the pause-squeeze technique in terms of IELT and sexual satisfaction score. In another study, Chen et al (2001) investigated the efficacy of sildenafil in the treatment of severe PE in 58 men who failed other treatment modalities, such as behavioral therapy, topi- cal lidocaine, tricyclic antidepressants, and SSRIs. Sildenafil was taken 1 hour before sexual activity in escalating dosing from 25 to $100 \mathrm{mg}$ until satisfactory ejaculation was attained. The authors concluded that sildenafil was useful in the treatment of PE for patients who have failed other remedies. In an extension to the previous study, Chen et al (2003) reported that sildenafil plus paroxetine had a higher success rate $(90 \%)$ than paroxetine alone in patients with severe PE. The therapeutic protocol involved taking paroxetine $20 \mathrm{mg}$ 7 hours before sexual intercourse and sildenafil 25-100 mg 1 hour before sexual activity.

Recently, in a well-designed study, Salonia et al (2002) compared paroxetine alone with paroxetine and sildenafil as an oral therapy for men reporting PE. In the combination group, paroxetine was given as $10 \mathrm{mg}$ once daily for 20 days, followed by $20 \mathrm{mg}$ as needed and sildenafil $50 \mathrm{mg}$ 1 hour before sexual activity. This study demonstrated that the combination of paroxetine and sildenafil obtained better results in regards to IELT and intercourse satisfaction than paroxetine alone. The combination treatment was associated with a mild increase in drug-related adverse events, such as headache (20\%), nausea (15\%), and flushing (15\%). Despite the higher incidence of adverse effects associated with the combined therapy, most patients $(90 \%)$ were willing to continue this treatment on an as-needed basis.

Another study that included 38 patients with secondary PE who were treated with sildenafil 50-100 mg alone found significant improvement in sexual satisfaction score and prolongation of mean IELT in 95\% of participants (Lobik et al 2003). The most recent combination study compared

Table I Doses and adverse effects of selective and nonselective serotonin reuptake inhibitors for treatment of PE

\begin{tabular}{|c|c|c|c|c|}
\hline Antidepressant ${ }^{a}$ & Recommended dose & $\begin{array}{l}\text { IELT increase } \\
\text { from baseline } \\
\text { ( } \approx \text { I minutes) }\end{array}$ & Side-effects & $\%$ side-effects \\
\hline $\begin{array}{l}\text { Clomipramine } \\
\left(\text { Anafranil }^{\circledR}\right)\end{array}$ & $\begin{array}{l}25-50 \mathrm{mg} / \mathrm{d} \text { or } 25 \mathrm{mg} \\
4-24 \text { hours pre-intecourse }\end{array}$ & $3-6$ minutes & $\begin{array}{l}\text { Dry mouth, drowsiness, } \\
\text { reduced potency, nausea, } \\
\text { vomiting, other }\end{array}$ & $60 \%$ \\
\hline $\begin{array}{l}\text { Fluoxetine } \\
\text { Prozac }^{\circledR} \text {, } \\
\text { Sarafem }^{\circledR} \text { ) }\end{array}$ & $5-20 \mathrm{mg} / \mathrm{d}$ & 2-9 minutes & $\begin{array}{l}\text { Drowsiness, dry mouth, } \\
\text { anejaculation, reduced } \\
\text { potency, nausea }\end{array}$ & $35 \%$ \\
\hline Paroxetine $\left(\mathrm{Paxil}^{\circledR}\right)$ & $\begin{array}{l}10-40 \mathrm{mg} / \mathrm{d} \text { or } 20 \mathrm{mg} \\
3-4 \text { hours pre-intercourse }\end{array}$ & $3-10$ minutes & $\begin{array}{l}\text { Anejaculation, nausea, } \\
\text { reduced libido, anorexia, } \\
\text { drowsiness, sensory } \\
\text { confusion }\end{array}$ & $15-65 \%$ \\
\hline Sertraline $\left(\right.$ Zoloft $^{\circledR}$ ) & $\begin{array}{l}25-200 \mathrm{mg} / \mathrm{d} \text { or } 50 \mathrm{mg} \\
4-8 \text { hours pre-intercourse }\end{array}$ & $3-6$ minutes & $\begin{array}{l}\text { Drowsiness, dry mouth, } \\
\text { anejaculation, reduced } \\
\text { potency, nausea }\end{array}$ & $30 \%$ \\
\hline
\end{tabular}

Derived from McMahon (1998), Kara et al (1996),Waldinger et al (1994), Strassberg et al (1999, 2005), Eli Lilly (2005), GlaxoSmithKline (2005), Pfizer, Inc (2005).

${ }^{a}$ The compounds are ordered alphabetically.

Abbreviations: IELT, intravaginal ejaculatory latency time; PE, premature ejaculation. 
sildenafil $25-100 \mathrm{mg}$ plus sertraline $50 \mathrm{mg}$ (48 patients) versus sertraline $50 \mathrm{mg}$ alone (51 patients) and sildenafil 50 $\mathrm{mg}$ alone (30 patients) in 3 different groups of PE patients (Lazona and Castane 2003). The highest success rate was observed in the group receiving sertraline plus sildenafil $(62.5 \%)$ followed by those receiving sertraline alone (56.8\%), and lastly those who received sildenafil alone (40\%).

There are several possible mechanisms that can explain the efficacy of sildenafil in the treatment of PE. Sildenafil may inhibit the contractile responses of the seminal vesicles, vas deferens, prostate, urethra, and even the skeletal muscles. Expression of PDE activity has been reported in the prostate, seminal vesicle, and skeletal muscles (Djoseland et al 1980; Stacey et al 1998; Yanaka et al 1998; Uckert et al 2001). PDE expression in vas deferens has not been studied yet; however, nitrergic innervation and nitric oxide synthase (NOS) activity have been localized to the human vas deferens, seminal vesicle, prostate, urethra, and skeletal muscles (Dixon and Jen 1995; Jen and Dixon 1995; Hedlund et al 1997; Jen et al 1997). In addition, evidence suggests that nitric oxide (NO) is the predominant inhibitory (relaxatory) neurotransmitter in the genitourinary organs (Naseem et al 2000; Andersson 2001). In male rats, NO and NO-donator agents were reported to inhibit seminal emission (Hull et al 1994). Furthermore, NO inhibitors increase the number of ex-copula seminal emissions and decrease the latency to seminal emission in the rat (Bialy et al 1996).

In animal studies, the cyclic nucleotides cyclic adenosine monophosphate (cAMP) and/or cyclic guanosine monophosphate (cGMP) relax the smooth muscle of the rat and guinea pig vas deferens (Schultz et al 1977; Stjarne et al 1979; Kato et al 2000). Sildenafil has been shown to cause potent and selective potentiation of nitrergic transmission in the urogenital muscles in male mice (Frith and Gibson 2000). As human seminal vesicle smooth muscle relaxation and modulation of ejaculation were reported to be regulated, in part, by increases of intracellular cGMP (Stjarne et al 1979). It is interesting to speculate on PDE-5 inhibitor action in this part of the body.

PDE-5 inhibitors are also postulated to inhibit adrenergic transmission in accessory sex organs (Takeda et al 1995). In in vitro studies, sildenafil inhibits adrenergic neurotransmission in the human vas deferens (Medina et al 2000). Furthermore, NO-donator agents diminish the adrenergic response in human seminal vesicles in vitro (Machtens et al 2003). Recently, sildenafil has been documented to exhibit a direct inhibitory action on smooth muscles tone of the human vas deferens, through activation of prejunctional $\mathrm{K}^{+}$channels (Medina et al 2000).

Sildenafil has also been shown to induce a state of peripheral analgesia via activation of the NO/cGMP signaling pathway in animals (Jain et al 2001). This effect could be instrumental in alleviating the penile hypersensivity that is reported in some patients with PE and may in turn mimic the success of topical anesthetics in the treatment of some PE patients (Berkovitch et al 1995).

Sildenafil has been reported to cause a clinically significant improvement in the total duration of erections during visual sexual stimulation when evaluated with sexual function questionnaires and Rigiscan devices (Boolell et al 1996; Sadovsky et al 2001). Because the ejaculatory latency time may be dependent on the duration of erection, any increase in the duration of erection may in turn prolong the ejaculatory latency time (Kameya et al 1997). In this regard, it is recognized that sildenafil may conceivably increase the ejaculatory latency time and contribute to prolongation of ejaculation.

Other PDE-5 inhibitors (tadalafil and vardenafil) have been evaluated for treatment of PE. Mattos and Lucon (2005) evaluated tadalafil alone and in combination with fluoxetine in $84 \mathrm{PE}$ patients without ED. The patients were randomly assigned in a double-blind manner into 4 groups: (1) tadalafil $20 \mathrm{mg}$ and fluoxetine $90 \mathrm{mg}$, (2) tadalafil $20 \mathrm{mg}$ and placebo, (3) fluoxetine $90 \mathrm{mg}$ and placebo, and (4) two different placebo capsules. Fluoxetine $90 \mathrm{mg}$ or placebo was given once a week, and tadalafil $20 \mathrm{mg}$ or placebo was given in a 36-hour frame of intended sexual intercourse. Mean baseline IELT was 55 seconds with stopwatch, and was not different between groups. The greatest increase from baseline IELT was observed in patients in the tadalafil plus fluoxetine group, followed by the fluoxetine only group, and the tadalafil-only group, respectively. This study demonstrates that tadalafil 20 $\mathrm{mg}$ once in 36 hours in combination with fluoxetine 90 in a slow-release form taken weekly can significantly increase IELT.

Sommer et al (2005) compared vardenafil $10 \mathrm{mg}(30$ minutes pre-intercourse) and sertraline $50 \mathrm{mg}$ (4 hours preintercourse) in a prospective, randomized, cross-over study. Ejaculation was assessed with IELT using a stopwatch and graded on a scale of 0 to $8(0=$ almost never, $8=$ almost always). The degree of improvement in ejaculation grade was 2.9 with vardenafil and 1.86 with sertraline, and the increases in IELT were 5.23 in vardenafil-treated patients and 2.87 in sertraline-treated patients. This study suggests that there is a potential for vardenafil in the treatment of PE. 


\section{Dapoxetine}

Although SSRIs are intended for chronic use in the treatment of depression and are designed to have pharmacokinetic profiles that would allow them to provide constant systemic concentration with long-term administration, they may need days to weeks to reach a maximum steady-state concentration in order to exhibit efficacy (Hiemke and Hartter 2000). Therefore, SSRIs are commonly used in a daily dosing schedule for the treatment of PE (Montague et al 2004). In addition to the potentially desirable side-effect of delaying ejaculation, this dosing regimen for long-acting SSRIs is associated with a number of undesirable side-effects, such as decreased libido and ED (Montague et al 2004). With the success of daily SSRI use in delaying ejaculation, it has been suggested that on-demand treatment with SSRIs possessing a short half-life and short $\mathrm{T}_{\max }$ would be equally effective, more convenient, and exhibit fewer serotonergic side-effects than observed with daily treatment (Waldinger 2005). Therefore, an ideal compound for the treatment of PE should exhibit pharmacokinetic profiles having rapid absorption, adequate availability to establish therapeutic exposure at the target site, and rapid elimination to reduce total drug exposure and minimize the incidence of side-effects (Modi et al 2006).

Dapoxetine, $((+)-(\mathrm{S})-\mathrm{N}, \mathrm{N}-$ dimethyl-(a)-[2-(1naphthalenyloxy)ethyl]-benzenemethanamine hydrochloride) is a novel potent serotonin transport inhibitor with a unique pharmacokinetic profile, and is currently in development for use in the treatment of PE (Dresser et al 2004; Gengo et al 2005). Dapoxetine hydrochloride is a water-soluble powder with a molecular weight of 341.88 and has a $\mathrm{pKa}$ of 8.6 and is mainly charged at a physiological $\mathrm{pH}$. These pharmacological characteristics allow for rapid distribution in the body and are different from the pharmacokinetics observed in conventional SSRIs. Dapoxetine is a fast-acting compound that attains its peak plasma concentration in about 1.5 hours after dosing, which is much faster than fluoxetine, paroxetine, or sertraline (Strassberg et al 1999, 2005; Eli Lilly 2005; GlaxoSmithKline 2005; Pfizer 2005). After oral administration, dapoxetine is readily absorbed, followed by a rapid decline in plasma concentrations. These pharmacokinetic properties make dapoxetine an excellent candidate for on-demand dosing, which avoids the potential disadvantages of continuous pharmacotherapy. The pharmacokinetic characteristics of dapoxetine compared with paroxetine and sertraline are provided in Table 2.

Although the pharmacological action of dapoxetine is similar to that of clomipramine and conventional SSRIs, the chemical structure and pharmacokinetic profile of dapox-
Table 2 Pharmacokinetic characteristics of dapoxetine compared with paroxetine and sertraline

\begin{tabular}{llll}
\hline & Dapoxetine & Paroxetine & Sertraline \\
\hline Dose $(\mathrm{mg})$ & 60 & 40 & 100 \\
$\mathrm{C}_{\max }(\mathrm{ng} / \mathrm{mL})$ & 386.0 & 19.0 & 22.7 \\
$\mathrm{~T}_{\text {max }}(\mathrm{h})$ & 1.5 & 6.83 & 6.4 \\
$\mathrm{~T}_{1 / 2 \mathrm{a}}(\mathrm{h})$ & 1.03 & 3.93 & 3.57 \\
$\mathrm{~T}_{1 / 2 \mathrm{~b}}(\mathrm{~h})$ & 21.9 & 46.7 & 39.5 \\
$\mathrm{C}_{24}(\%$ of peak) & 3.67 & 45.1 & 47.8 \\
Accumulation & 1.3 & 2.45 & 2.68
\end{tabular}

Derived from Gengo et al (2005), Hellstrom (2004), Hellstrom et al (2005), Andersson et al (2006).

etine differentiates it from other SSRIs. Dapoxetine is not a halogenated compound, whereas others contain one or more halogen atoms. The molecular structure of dapoxetine also includes a naphthyl moiety and it is possible that these features underpin the physicochemical and pharmacokinetic properties of the molecule.

Dapoxetine is a potent inhibitor of the 5-HT reuptake transporter. Studies conducted in cells expressing the human transcript of the 5-HT, norepineprine, and dopamine reuptake reporters to determine the inhibition constant $\left(\mathrm{K}_{\mathrm{i}}\right)$ and the activity of dapoxetine $\left(\mathrm{IC}_{50}\right)$ values showed that dapoxetine competed in a concentration-dependent manner for specific $\left[{ }^{3} \mathrm{H}\right]$ citalopram binding sites on the 5-HT reuptake transporter $\left(\mathrm{K}_{\mathrm{i}}=9.5\right)$, specific $\left[{ }^{3} \mathrm{H}\right]$ nisoxatine binding sites on the norepinephrine reuptake transporter $\left(\mathrm{K}_{\mathrm{i}}=6.6\right)$, and specific $\left[{ }^{3} \mathrm{H}\right]$ WIN35428 binding sites on the dopamine reuptake transporter $\left(\mathrm{K}_{\mathrm{i}}=5.8\right)$ (Gengo et al 2005). Additionally, dapoxetine inhibited the uptake of $\left[{ }^{3} \mathrm{H}\right] 5-\mathrm{HT}$ by the 5-HT reuptake transporter with a value of $1.12 \mathrm{nM}$, whereas the uptake of $\left[{ }^{3} \mathrm{H}\right]$ norepinephrine into cells utilizing the norepinephrine reuptake transporter and uptake of $\left[{ }^{3} \mathrm{H}\right]$ dopamine by the dopamine reuptake transporter were inhibited by dapoxetine with IC50 values of $202 \mathrm{nM}$ and $1720 \mathrm{nM}$, respectively. In conclusion, dapoxetine binds to 5-HT, norepinephrine, and dopamine reuptake transporters and inhibits 5-HT, norepinephrine, and dopamine uptake with an order of potency: 5-HT $>$ norepinephrine $>$ dopamine.

A double-blind, randomized, placebo-controlled, crossover, 3-period phase II US study of dapoxetine for the treatment of PE, comparing the safety and efficacy of ondemand dapoxetine $60 \mathrm{mg}$ versus $100 \mathrm{mg}$ versus placebo was presented (Hellstrom 2004). Each of the three 2-week treatment periods was separated by a 72-hour washout period. The patients enrolled in the study were all heterosexual 
men aged 18-65 years who had been involved in a stable, monogamous relationship for at least 6 months and whose baseline IELT was under 2 minutes, as measured by the partner using a stopwatch. The primary endpoint was IELT, as well as patients' satisfaction control over ejaculation. A total of 130 men with PE completed the study. The mean baseline IELT increased from 1.01 minutes to 2.94 minutes with $60 \mathrm{mg}$ dapoxetine, 3.20 minutes with $100 \mathrm{mg}$ dapoxetine, and 2.05 minutes with placebo ( $\mathrm{p}<0.0001$ vs placebo). Patients who received the 60-mg dose of dapoxetine reported significant increases in their control over ejaculation from baseline $(\mathrm{p}<0.0001)$ and significant benefits in their sexual satisfaction (with their sexual intercourse episodes). Nausea, the most common reported adverse effect, occurred in 5.6\% of patients who received $60 \mathrm{mg}, 16.1 \%$ of those who received $100 \mathrm{mg}$, and $0.7 \%$ of those who received placebo (Table 3 ) (Hellstrom 2004). Of the 10 patients who discontinued the study because of side-effects, 9 were receiving the $100-\mathrm{mg}$ dose of dapoxetine and 1 patient was receiving placebo.

Another two phase II clinical trials investigated the efficacy and tolerability of 20, 40,60, and $100 \mathrm{mg}$ dapoxetine in order to determine the appropriate on-demand doses of dapoxetine for further study in large-scale phase III clinical trials (Hellstrom et al 2005). Both double-blind, multi-center, randomized, placebo-controlled, 3-period cross-over phase II studies enrolled men with PE, based on DSM-IV-TR criteria and IELT. Subjects were instructed to take study drug prior to the anticipated sexual intercourse (1-3 hours prior in

Table 3 Adverse events observed with dapoxetine $(60 \mathrm{mg}$ and $100 \mathrm{mg}$ ) and placebo

\begin{tabular}{|c|c|c|c|}
\hline Adverse effects & $\begin{array}{l}\text { Placebo } \\
(n=\mid 40)\end{array}$ & $\begin{array}{l}\text { Dapoxetine } \\
60 \mathrm{mg} \\
(\mathrm{n}=139)\end{array}$ & $\begin{array}{l}\text { Dapoxetine } \\
\text { I00 mg } \\
(\mathrm{n}=\mid 45)\end{array}$ \\
\hline Total \# of pts I AE & 21 (15.0\%) & $41(29.5 \%)$ & 57 (39.3\%) \\
\hline Nausea & I $(0.7 \%)$ & $8(5.8 \%)$ & $24(16.6 \%)$ \\
\hline Headache & 0 & $6(4.3 \%)$ & $8(5.5 \%)$ \\
\hline \multicolumn{4}{|l|}{ Upper respiratory } \\
\hline tract infection & I (0.7\%) & $3(2.2 \%)$ & $2(1.4 \%)$ \\
\hline Diarrhea & I (0.7\%) & $7(5.0 \%)$ & $10(6.9 \%)$ \\
\hline Dizziness & 0 & $3(2.2 \%)$ & $2(1.4 \%)$ \\
\hline Rhinitis & I (0.7\%) & $6(4.3 \%)$ & I $(0.7 \%)$ \\
\hline ED & 0 & 0 & $2(1.4 \%)$ \\
\hline Somnolence & I (0.7\%) & $4(2.9 \%)$ & $2(1.4 \%)$ \\
\hline Insomnia & I (0.7\%) & $5(3.6 \%)$ & $9(6.2 \%)$ \\
\hline Dyspepsia & 0 & $4(2.9 \%)$ & $3(2.1 \%)$ \\
\hline Nervousness & 0 & $5(3.6 \%)$ & $5(3.4 \%)$ \\
\hline Dropouts & I & 0 & 9 \\
\hline
\end{tabular}

Derived from Hellstrom (2004), Hellstrom et al (2005).

Abbreviations: $\mathrm{AE}$, adverse events; $\mathrm{ED}$, erectile dysfunction. study 1, and 1-2 hours prior in study 2) and to attempt sexual intercourse $\geq$ twice weekly. The primary endpoint was IELT measured with a stopwatch held by the female partner. In study 1, 128 of 157 patients (20 $\mathrm{mg}$ and $40 \mathrm{mg}$ dapoxetine), and in study 2, 130 of 166 (60 $\mathrm{mg}$ and $100 \mathrm{mg}$ dapoxetine) randomized subjects completed the trials. All four doses of dapoxetine documented statistically significant improvements in IELT over placebo (Table 4).

In a recent study by Pryor et al (2005), the efficacy and tolerability of dapoxetine in the treatment of PE were evaluated. Men with PE $(n=2614)$ as defined by DSM-IVTR criteria were enrolled in 2 randomized, double-blind, placebo-controlled, multi-center, phase III clinical trials of identical design, and each had a 2 -week baseline period and 12-week treatment period. At the end of the baseline period, subjects with mean IELT $\geq 2$ minutes were randomized 1:1:1 to placebo, dapoxetine $30 \mathrm{mg}$, or $60 \mathrm{mg}$, and instructed to take the study drug 1-3 hours prior to anticipated sexual intercourse. The primary efficacy endpoint was IELT adjusted for baseline, as measured by a stopwatch held by the female partner. Secondary endpoints were subjective perception of Control Over Ejaculation and Satisfaction With Sexual Intercourse, and were assessed at baseline, 4, 8, and 12 weeks, and rated on 5-point scales of between 0 (very poor) and 4 (very good). Preliminary results of this study demonstrated that there were significant differences between placebo and each active treatment group in mean IELT, Control Over Ejaculation, and Satisfaction With Sexual Intercourse ( $p<0.0001)$. Changes from baseline to study end point for mean IELT were 0.90-1.75 min (placebo), 0.92-2.78 minutes (30 mg dapoxetine), and 0.91-3.32 minutes (60 mg dapoxetine). Both dapoxetine $30 \mathrm{mg}$ and 60 were found to be more effective than placebo in increasing IELT on first dose. Treatment-related side-effects (incidence $\geq 5 \%$ ) with both $30 \mathrm{mg}$ and $60 \mathrm{mg}$ dapoxetine were nausea $(8.7 \%$ and $20.1 \%$ ), headache $(5.9 \%$ and $6.8 \%)$, diarrhea $(6.8 \%$ with $60 \mathrm{mg}$ ), and dizziness (6.2\% with $60 \mathrm{mg})$. Discontinuation rates due to adverse effect were reported as $0.0 \%, 4 \%$, and $10 \%$ for placebo, $30 \mathrm{mg}$, and $60 \mathrm{mg}$ doses of dapoxetine, respectively. The authors concluded that dapoxetine $30 \mathrm{mg}$ or $60 \mathrm{mg}$ is effective for the on-demand treatment of PE, with increased IELT, improved Control Over Ejaculation, and increased Satisfaction With Sexual Intercourse.

The use of ethanol and PDE-5 inhibitors with sexual activity is recognized. The interactions of dapoxetine with PDE-5 inhibitors and ethanol have also been investigated. The effects of PDE-5 inhibitors on the pharmacokinetics of dapoxetine were studied in a randomized, open-label, 
Table 4 The efficacy of various doses of dapoxetine on IELT

\begin{tabular}{|c|c|c|}
\hline Results & Study I & Study 2 \\
\hline Age range & $18-60$ years & $18-65$ years \\
\hline IELT for inclusion & 2 min estimated & 2 min stopwatch \\
\hline Treatment period & 4 wk per treatment & 2 wk per treatment \\
\hline Washout period & None & $72 \mathrm{~h}$ \\
\hline Dapoxetine dose & $20 \mathrm{mg} 40 \mathrm{mg}$ Placebo & $60 \mathrm{mg} 100 \mathrm{mg}$ Placebo \\
\hline ( $n=$ per group) & $(n=145) \quad(n=141) \quad(n=142)$ & $(n=144) \quad(n=155) \quad(n=145)$ \\
\hline Mean baseline IELT & $\begin{array}{lll}\mathrm{I} .34 & \mathrm{I} .34 & \mathrm{I} .34\end{array}$ & $\begin{array}{lll}1.01 & 1.01 & 1.01\end{array}$ \\
\hline Mean in from baseline IELT & $1.38 * \quad 1.97 * * \quad 0.88$ & $1.95 * * \quad 2.23 * * \quad 1.06$ \\
\hline Discontinuation due to $\mathrm{AE}$ & 20 & $\begin{array}{lll}0 & 9 & 1\end{array}$ \\
\hline
\end{tabular}

Derived from Hellstrom (2004), Hellstrom et al (2005).

$*_{p}=0.042$ vs placebo

$* * \mathrm{p}<0.000$ I vs placebo.

Abbreviations: AE, adverse events; IELT, intravaginal ejaculatory latency time.

3 -period crossover study in healthy male subjects $(\mathrm{n}=24$; $18-45$ years of age) receiving a single $60-\mathrm{mg}$ dose of dapoxetine, dapoxetine $60 \mathrm{mg}$ plus sildenafil $100 \mathrm{mg}$, and dapoxetine $60 \mathrm{mg}$ plus tadalafil $20 \mathrm{mg}$ (Dresser et al 2006). Each treatment was separated by a 6- to 14-day washout period. Blood samples were collected predose and at specified times after dosing for measurement of dapoxetine and its metabolites and tadalafil and sildenafil plasma concentrations. This study demonstrated that sildenafil and tadalafil did not have a clinically significant effect on the pharmacokinetics of dapoxetine. In the other study that was designed as double-blind, randomized, and 4-period crossover in healthy male adult subjects, the effect of ethanol on the pharmacokinetics of dapoxetine was investigated (Modi et al 2005). Each separate treatment period of a single dose of dapoxetine $60 \mathrm{mg}$ and a single dose of $0.5 \mathrm{~g} / \mathrm{kg}$ ethanol, dapoxetine $60 \mathrm{mg}$ and ginger ale (placebo for ethanol), placebo (for dapoxetine) and 0.5 $\mathrm{g} / \mathrm{kg}$ ethanol, and placebo for both drugs was administered with a 5- to 21-day washout period. Safety was assessed by adverse event reporting throughout the study and by laboratory tests, and blood samples were collected predose and at specified times after for measurement of plasma concentrations of dapoxetine and its metabolites and ethanol analysis. The results of this study demonstrated that co-administration of ethanol with dapoxetine did not produce significant changes in dapoxetine pharmacokinetics.

\section{Conclusions}

Neurobiological studies in animals and humans have provided better understanding of the physiology of ejaculation and pathophysiology of PE. The nature of PE is such that patients should not have to chronically take potent psychoactive drugs, with long-lasting actions and debilitating side-effects. Dapoxetine is a selective serotonin transport inhibitor with unique pharmacokinetic and pharmocodynamic properties that account for its clinical effects. Future studies may demonstrate whether dapoxetine could possess many of the attributes of an ideal compound for the treatment of PE.

\section{References}

[APA] American Psychiatric Association. 2000. The Diagnostic and Statistical Manual of Mental Disorders. 4th ed. Washington, DC: American Psychiatric Association.

Abdel-hamid IA, El Naggar EA, El Gilany AH. 2001. Assessment of as needed use of pharmacotherapy and the pause-squeeze technique in premature ejaculation. Int J Impot Res, 13:41-5.

Ahlenius S, Larsson K, Svensson L, et al. 1981. Effects of a new type of 5 -HT receptor agonist on male rat sexual behavior. Pharmacol Biochem Behav, 15:785-92.

Andersson KE. 2001. Neurotransmission and drug effects in urethral smooth muscle. Scand J Urol Nephrol Suppl, 26-34; discussion 106-25.

Andersson KE, Mulhall JP, Wyllie MG. 2006. Pharmacokinetic and pharmacodynamic features of dapoxetine, a novel drug for 'on-demand' treatment of premature ejaculation. BJU Int, 97:311-5.

Berendsen HH, Broekkamp CL. 1994. Comparison of stimulus properties of fluoxetine and 5-HT receptor agonists in a conditioned taste aversion procedure. Eur J Pharmacol, 253:83-9.

Berkovitch M, Keresteci AG, Koren G. 1995. Efficacy of prilocaine-lidocaine cream in the treatment of premature ejaculation. J Urol, 154:1360-1.

Bialy M, Beck J, Abramczyk P, et al. 1996. Sexual behavior in male rats after nitric oxide synthesis inhibition. Physiol Behav, 60:139-43.

Boolell M, Allen MJ, Ballard SA, et al. 1996. Sildenafil:an orally active type 5 cyclic GMP-specific phosphodiesterase inhibitor for the treatment of penile erectile dysfunction. Int J Impot Res, 8:47-52.

Bradley WE, Farrell DF, Ojemann GA. 1998, Human cerebrocortical potentials evoked by stimulation of the dorsal nerve of the penis. Somatosens Mot Res, 15:118-27.

Carson C, Glasser DB, Laumann EO, et al. 2003. Prevalence and correlates of premature ejaculation among men aged 40 years and older: a United States nationwide population-based study [abstract]. J Urol, Abstract 1249.

Chen J, Greenstein A, Mabjeesh NJ, et al. 2001. Role of sildenafil treatment in premature ejaculation. Int J Impot Res, 13:548

Chen J, Mabjeesh NJ, Matzkin H, et al. 2003 Efficacy of sildenafil as adjuvant therapy to selective serotonin reuptake inhibitor in alleviating premature ejaculation. Urology, 61:197-200.

Choi HK, Jung GW, Moon KH, et al. 2000. Clinical study of SS-cream in patients with lifelong premature ejaculation. Urology, 55:257-61.

Coffey DS. 1988. Androgen action and the sex accessory tissues. New York: Raven Press. 
Dixon JS, Jen PY. 1995. Development of nerves containing nitric oxide synthase in the human male urogenital organs. Br J Urol, 76:719-25.

Djoseland O, Gordeladze JO, Hoglo S, et al. 1980. Evidence for androgen-dependent phosphodiesterase activity in rat seminal vesicle and epididymis. Int $J$ Androl, 3:363-6.

Dresser M, Lindert K, Lin D, et al. 2004. Pharmacokinetics of single and multiple escalating doses of dapoxetine in healthy volunteers [online]. Accessed Jan 21 2005. URL: http://ascpt.org/pres/2004/2004Abstracts.pdf.

Dresser MJ, Desai D, Gidwani S, et al. 2006. Dapoxetine, a novel treatment for premature ejaculation, does not have pharmacokinetic interactions with phosphodiesterase-5 inhibitors. Int J Impot Res, 18:104-10.

Eli Lilly and Company. 2005. Prozac (fluoxetine hydrochloride) prescribing information. Indianapolis, Ind [online]. Accessed 11 April 2007. URL: http://pi.lilly.com/us/prozac.pdf.

Foreman MM, Hall JL, Love RL. 1989. The role of the 5-HT2 receptor in the regulation of sexual performance of male rats. Life Sci, 45:1263-70.

Frith D, Gibson A. 2000. Sildenafil citrate on nitrergic transmission in anococcygeus muscles from the urogenital system of male and female mice. Eur J Pharmacol, 400:305-12.

Gengo PJ, Giuliano F, McKenna KE, et al. 2005. Monoaminergic transporter binding and inhibition profile of dapoxetine, a medication for the treatment of premature ejaculation [abstract]. J Urol, 173:239, Abstract 878 .

GlaxoSmithKline. 2005. Paxil (paroxetine hydrochloride) Tablets and oral suspension prescribing information [online]. Accessed 11 April 2007. URL: http://us.gsk.com/products/assetts/us_paxil.pdf.

Godpodinoff ML. 1989. Premature ejaculation:clinical subgroups and etiology. J Sex Marital Ther, 15:130-4.

Goldstein I. 2003. Premature to early ejaculation: a sampling of manuscripts regarding the most common male sexual dysfunction published in the IJIR: The Journal of Sexual Medicine. Int J Impot Res, 15:307-8.

Haensel SM, Rowland DL, Kallan KT. 1996. Clomipramine and sexual function in men with premature ejaculation and controls. $J$ Urol, 156:1310-5.

Hedlund P, Ekstrom P, Larsson B, et al. 1997. Heme oxygenase and NOsynthase in the human prostate--relation to adrenergic, cholinergic and peptide-containing nerves. J Auton Nerv Syst, 63:115-26.

Hellstrom WJ. 2004. Dapoxetine $\mathrm{HCl}$ for the treatment of premature ejaculation:a phase II, randomized, double-blind, placebo-controlled study. J Sex Med.

Hellstrom WJ, Althof S, Gittelman M, et al. 2005. Dapoxetine for the treatment of men with premature ejaculation:Dose-finding analysis. $A U A$ Annual Meeting. San Antonio, TX.

Hiemke C, Hartter S. 2000. Pharmacokinetics of selective serotonin reuptake inhibitors. Pharmacol Ther, 85:11-28.

Hsieh JT, Chang HC, Law HS, et al. 1998. In vivo evaluation of serotonergic agents and alpha-adrenergic blockers on premature ejaculation by inhibiting the seminal vesicle pressure response to electrical nerve stimulation. Br J Urol, 82:237-40.

Hull EM, Lumley LA, Matuszewich L, et al. 1994. The roles of nitric oxide in sexual function of male rats. Neuropharmacology, 33:1499-504.

Jain NK, Patil CS, Singh A, et al. 2001. Sildenafil-induced peripheral analgesia and activation of the nitric oxide-cyclic GMP pathway. Brain Res, 909:170-8.

Jannini EA, Simonelli C, Lenzi A. 2002. Disorders of ejaculation. J Endocrinol Invest, 25:1006-19.

Jen PY, Dixon JS. 1995. Development of peptide-containing nerves in the human fetal prostate gland. $J$ Anat, 187:169-79.

Jen PY, Dixon JS, Gosling JA. 1997. Co-localization of nitric oxide synthase, neuropeptides and tyrosine hydroxylase in nerves supplying the human post-natal vas deferens and seminal vesicle. Br J Urol, 80:291-9.

Kameya Y, Deguchi A, Yokota Y. 1997. Analysis of measured values of ejaculation time in healthy males. $J$ Sex Marital Ther, 23:25-8.

Kaplan HS, Kohl RN, Pomeroy WB, et al. 1974. Group treatment of premature ejaculation. Arch Sex Behav, 3:443-52.
Kara H, Aydin S, Yucel M, et al. 1996. The efficacy of fluoxetine in the treatment of premature ejaculation:a double-blind placebo controlled study. J Urol, 156:1631-2.

Kato K, Furuya K, Tsutsui I, et al. 2000. Cyclic AMP-mediated inhibition of noradrenaline-induced contraction and $\mathrm{Ca}_{2}{ }^{+}$influx in guinea-pig vas deferens. Exp Physiol, 85:387-98.

Kim SC, Seo KK. 1998. Efficacy and safety of fluoxetine, sertraline and clomipramine in patients with premature ejaculation:a double-blind, placebo controlled study. J Urol, 159:425-7.

Kim SC, Seo KK, Han JH, et al. 2000. Inhibitory effect of serotonergic drugs on contractile response of the rat vas deferens to electrical nerve stimulation:in vivo study. J Urol, 163:1988-91.

Kim SW, Lee SH, Paick JS. 2004. In vivo rat model to measure hypogastric nerve stimulation-induced seminal vesicle and vasal pressure responses simultaneously. Int J Impot Res, 16:427-32.

Laumann EO, Nicolosi A, Glasser DB, et al. 2005. Sexual problems among women and men aged 40-80 y:prevalence and correlates identified in the Global Study of Sexual Attitudes and Behaviors. Int J Impot Res, 17:39-57.

Laumann EO, Paik A, Rosen RC. 1999. Sexual dysfunction in the United States:prevalence and predictors. JAMA, 281:537-44.

Lazona AF, Castane ER. 2003. Premature ejaculation:sildenafil plus sertraline versus sertraline alone and sildenafil alone [Abstract 956]. J Urol, 169:247.

Lobik L, Cytron S, Kravchick S, et al. 2003. The effect of sildenafil citrate in the treatment of secondary rapid ejaculation. $J$ Urol, 13:378.

Machtens S, Ckert S, Stief CG, et al. (2003) Effects of various nitric oxidedonating drugs on adrenergic tension of human seminal vesicles in vitro. Urology, 61:479-83.

McMahon CG. 1998. Treatment of premature ejaculation with sertraline hydrochloride. Int J Impot Res, 10:181-4; discussion 185.

McMahon CG, Abdo C, Incrocci L, et al. 2004. Disorders of orgasm and ejaculation. J Sex Med, 1:58-65.

McMahon CG, Touma K. 1999. Treatment of premature ejaculation with paroxetine hydrochloride as needed: 2 single-blind placebo controlled crossover studies. J Urol, 161:1826-30.

Mallinckrodt Pharmaceuticals. 2007. Anafranil (Clomipramine Hydrochloride Capsules USP $25 \mathrm{mg}, 50 \mathrm{mg}$, and $75 \mathrm{mg}$ ) Rx only. Prescribing information [online]. Accessed 4 April 2007. URL: http://pharmaceuticals.mallinckrodt. com/_attachments/Packagelnserts/01\%20Anafrenil\%20REV\%20020305. pdf. Masters WH, Johnson VE. 1970. Human Sexual Inadequacy. Boston: Little, Brown and Co.

Mattos RM, Lucon AM. 2005. Tadalafil and slow-release fluoxetine in premature ejaculation:a prospective study. AUA Annual Meeting. San Antonio, TX.

Medina P, Segarra G, Torondel B, et al. 2000. Inhibition of neuroeffector transmission in human vas deferens by sildenafil. Br J Pharmacol, 131:871-4

Modi NB, Dresser M, Desai D, et al. 2005. Dapoxetine for the treatment of premature ejaculation:Lack of interaction with ethanol [abstract]. J Urol, 173:239, Abstract 879.

Modi NB, Dresser MJ, Simon M, et al. 2006. Single- and multiple-dose pharmacokinetics of dapoxetine hydrochloride, a novel agent for the treatment of premature ejaculation. J Clin Pharmacol, 46:301-9.

Montague DK, Jarow J, Broderick GA, et al. 2004. AUA guideline on the pharmacologic management of premature ejaculation. J Urol, 172:290-4.

Mos J, Mollet I, Tolboom JT, et al. 1999. A comparison of the effects of different serotonin reuptake blockers on sexual behaviour of the male rat. Eur Neuropsychopharmacol, 9:123-35.

Naseem KM, Mumtaz FH, Thompson CS, et al. 2000. Relaxation of rabbit lower urinary tract smooth muscle by nitric oxide and carbon monoxide: modulation by hydrogen peroxide. Eur J Pharmacol, 387:329-35.

Pfizer, Inc. 2005. Zoloft (sertraline hydrochloride) Tablets and Oral Concentrate prescribing information [online]. Accessed 11 April 2007. URL: http://www.zoloft.com/ZoloftUSPI.pdf. 
Pryor JL, Althof S, Steidle C, et al. 2005. Efficacy and tolerability of dapoxetine in the treatment of premature ejaculation [abstract]. J Urol, 173:201, Abstract 740

Rosen RC, Porst H, Montorsi F. 2004. The Premature Ejaculation Prevalence and Attitudes (PEPA) Survey: A multinational survey. $J$ Sex Med, 1(suppl 1):57-8.

Rowland DL, Perelman M, Althof S, et al. 2004. Self-reported premature ejaculation and aspects of sexual functioning and satisfaction. $J$ Sex Med, 1:225-232.

Sadovsky R, Miller T, Moskowitz M, et al. 2001. Three-year update of sildenafil citrate (Viagra) efficacy and safety. Int J Clin Pract, 55:115-28.

Salonia A, Maga T, Colombo R, et al. 2002. A prospective study comparing paroxetine alone versus paroxetine plus sildenafil in patients with premature ejaculation. $J$ Urol, 168:2486-9.

Schultz K, Schultz K, Schultz G. 1977. Sodium nitroprusside and other smooth muscle-relaxants increase cyclic GMP levels in rat ductus deferens. Nature, 265:750-1.

Segraves RT, Saran A, Segraves K, et al. 1993. Clomipramine versus placebo in the treatment of premature ejaculation: a pilot study. J Sex Marital Ther, 19:198-200.

Shabsigh R, Perelman M. 2005. Men with both premature ejaculation (PE) and erectile dysfunction (ED) experience lower quality-of-life than men with either PE or ED alone. World Congress of Sexology. Montreal, Canada.

Shafik A. 1997. Pelvic floor muscles and sphincters during erection and ejaculation. Arch Androl, 39:71-8.

Shafik A. 1998. The mechanism of ejaculation:the glans-vasal and urethromuscular reflexes. Arch Androl, 41:71-8.

Sharlip I. 2005. Diagnosis and treatment of premature ejaculation:the physician's perspective. J Sex Med, 2(Suppl 2):103-9.

Shenassa B, Hellstrom WJ. 2001. Understanding ejaculatory disorders. Contemp Urol, 13:51-59.

Sommer F, Klotz T. Mathers MJ. 2005. Treatment of premature ejaculation:a comperative vardenafil and SSRI crossover study. AUA Annual Meeting. San Antonio, TX.

Stacey P, Rulten S, Dapling A. et al. 1998. Molecular cloning and expression of human cGMP-binding cGMP-specific phosphodiesterase (PDE5). Biochem Biophys Res Commun, 247:249-54.

Stjarne L, Bartfai T, Alberts P. 1979. The influence of 8-Br 3', 5'-cyclic nucleotide analogs and of inhibitors of 3', 5'-cyclic nucleotide phosphodiesterase, on noradrenaline secretion and neuromuscular transmission in guinea-pig vas deferens. Naunyn Schmiedebergs Arch Pharmacol, 308:99-105.

Strassberg DS, de Gouveia Brazao CA, Rowland DL, et al. 1999. Clomipramine in the treatment of rapid (premature) ejaculation. J Sex Marital Ther, 25:89-101.

Symonds T, Roblin D, Hart K, et al. 2003. How does premature ejaculation impact a mans life? J Sex Marital Ther, 29:361-70.

Takeda M, Tang R, Shapiro E, et al. 1995. Effects of nitric oxide on human and canine prostates. Urology, 45:440-6.

Uckert S, Kuthe A, Jonas U, et al. 2001. Characterization and functional relevance of cyclic nucleotide phosphodiesterase isoenzymes of the human prostate. $J$ Urol, 166:2484-90.

Waldinger MD. 2002. The neurobiological approach to premature ejaculation. J Urol, 168:2359-67.
Waldinger MD. 2003. Towards evidence-based drug treatment research on premature ejaculation:a critical evaluation of methodology. Int J Impot Res, 15:309-13.

Waldinger MD. 2005. Lifelong premature ejaculation:definition, serotonergic neurotransmission and drug treatment. World J Urol, 23:102-8.

Waldinger MD, Berendsen HH, Blok BF, et al. 1998a. Premature ejaculation and serotonergic antidepressants-induced delayed ejaculation:the involvement of the serotonergic system. Behav Brain Res, 92:111-8.

Waldinger MD, Hengeveld MW, Zwinderman AH. 1994. Paroxetine treatment of premature ejaculation:a double-blind, randomized, placebocontrolled study. Am J Psychiatry, 151:1377-9.

Waldinger MD, Hengeveld MW, Zwinderman AH, et al. 1998b. Effect of SSRI antidepressants on ejaculation:a double-blind, randomized, placebo-controlled study with fluoxetine, fluvoxamine, paroxetine, and sertraline. J Clin Psychopharmacol, 18:274-81.

Waldinger MD, Quinn P, Dilleen M, et al. 2005a. A multinational population survey of intravaginal ejaculation latency time. $J$ Sex Med, 2:492-7.

Waldinger MD, Schweitzer DH. 2005. Retarded ejaculation in men:an overview of psychological and neurobiological insights. World J Urol, 23:76-81.

Waldinger MD, Schweitzer DH, Olivier B. 2005b. On-demand SSRI treatment of premature ejaculation:pharmacodynamic limitations for relevant ejaculation delay and consequent solutions. $J$ Sex Med, 2:121-31.

Waldinger MD, van de Plas A, Pattij T, et al. 2002.The selective serotonin re-uptake inhibitors fluvoxamine and paroxetine differ in sexual inhibitory effects after chronic treatment. Psychopharmacology (Berl), 160:283-9.

Waldinger MD, Zwinderman AH,Olivier B. 2004a.On-demand treatment of premature ejaculation with clomipramine and paroxetine:a randomized, double-blind fixed-dose study with stopwatch assessment. Eur Urol, 46:510-5; discussion 516.

Waldinger MD, Zwinderman AH, Olivier B, et al. 2005c. Proposal for a definition of lifelong premature ejaculation based on epidemiological stopwatch data. J Sex Med, 2:498-507.

Waldinger MD, Zwinderman AH, Schweitzer DH, et al. 2004b. Relevance of methodological design for the interpretation of efficacy of drug treatment of premature ejaculation:a systematic review and meta-analysis. Int J Impot Res, 16:369-81.

Williams W. 1984. Secondary premature ejaculation. Aust NZJ Psychiatry, 18:333-40.

Witt MA, Grantmyre JE. 1993. Ejaculatory failure. World J Urol, 11:89-95.

Xin ZC, Choi YD, Lee SH, et al. 1997. Efficacy of a topical agent SS-cream in the treatment of premature ejaculation: preliminary clinical studies. Yonsei Med J, 38:91-5.

Yanaka N, Kotera J, Ohtsuka A, et al. 1998. Expression, structure and chromosomal localization of the human cGMP-binding cGMP-specific phosphodiesterase PDE5A gene. Eur J Biochem, 255:391-9.

Yang CC, Bradley WE. 1999. Somatic innervation of the human bulbocavernosus muscle. Clin Neurophysiol, 110:412-8. 
